\title{
The Role of Customer-Task Fit Between Service Interaction and Value Co-Creation: Evidence From China
}

\author{
Liang Hong, Anqing Normal University, China \\ Hongyan Yu, Sun Yat-sen University, China \\ Yubing Yu, Zhejiang Wanli University, China \\ Peipei Liang, Anqing Normal University, China \\ Junjie Xu, Anqing Normal University, China
}

\begin{abstract}
As a new value creation phenomenon, value co-creation has been widely studied by academia and industry. Companies have begun to invest significant resources and build information exchange platforms to interact with customers in order to gain competitive advantage. However, prior research has ignored the underlying mechanism by which service interaction might improve value co-creation. Based on the person-environment fit theory, an attempt is made to investigate the intervening role of customer-task fit, which includes demand-ability fit and needs-supply fit to explain the above linkage. With 509 customer questionnaires collected from China, the results showed that service interaction has both direct and indirect effects on value co-creation, and needs-supply fit partially mediates the relationship of service interaction and value co-creation. In addition, results supported the serial mediation model where service interaction was found to exercise its influence on value co-creation via demand-ability fit and needs-supply fit in a sequential manner.
\end{abstract}

\section{KEYWORDS}

Person-Environment Fit, Service Interaction, Value Co-Creation

\section{INTRODUCTION}

Under the service-dominant logic, enterprises can offer their applied resources for value creation and collaboratively (i.e., interactively) create value following the acceptance of value propositions but cannot create or deliver value independently, and the customer is always a co-creator of value (Vargo $\&$ Lusch, 2008). A large number of enterprises began to build information exchange platforms to interact with their customers and co-create value together, then, learning to co-create with customers became a new competitive advantage (Randall \& Robert, 2004). For example, many enterprises are eager to collect customer information and promote connections between customers and companies, brands, and products through interactions, thereby gradually increasing the mutual benefit.

As a key in services marketing, interactions have been defined in the concept of service encounter (Lovelock \& Wirtz, 2010), which include the interactions between customers and employees and

DOI: 10.4018/JGIM.20211101.oa44

This article published as an Open Access article distributed under the terms of the Creative Commons Attribution License (http://creativecommons.org/licenses/by/4.0/) which permits unrestricted use, distribution, and production in any medium, provided the author of the original work and original publication source are properly credited. 
between customers and non-interpersonal environment (Shostack, 1985). This article focuses on the former, because it is particularly important to the evaluation of service, which is about information exchange, collaboration, and cooperation (Nardi et al., 2019). Although service interaction has received a lot of attention, interactions do not necessarily have positive effects (Ennew \& Binks, 1999; Bendapudi \& Leone, 2003). In many cases, the processes of service interactions are not as good as enterprises expect (Dong et al., 2015), which has led to waste marketing resources with little effect (Guo \& Sun, 2012). The possible explanation is that interaction is just a platform for value creation by organizations and customers, and it does not mean the two sides will make automatic impacts on each other (Grönroos \& Voima, 2013).

Therefore, it is necessary to understand how service interaction improves value co-creation. However, previous research has neglected the mechanism behind this link, and there are only a few analyses (Chan, Chi, \& Lam, 2010; Chi \& Lam, 2012), except that some scholars explored this link from the perspective of resource integration (Davey \& Gronroos, 2019). Then, interactions between participants can facilitate resource integration through dialogue, resource transfer and learning, which further influences value co-creation. However, the key to resource integration is the fit between or the consonance of resources, processes, and goals (Gummesson \& Mele, 2010).

The concept of fit originates from interactive psychology (Cheng-Ping, 2018), which refers to the interactions between person and environment, such as person-job fit (Bhat \& Rainayee, 2017) and person-organization fit (Kristof, 1996). Person-environment fit is generally defined as the compatibility between individuals and their environment (Van Vianen, 2018), suggests that "people have an innate need to fit their environments and to seek out environments that match their own characteristics" (Gander et al., 2020). The fit between person and environment is widely believed to have a positive impact on attitudes, behaviors, and performance (Kristof et al., 2005; Van Vianen, 2018). Although person-environment fit theory has been widely used in the work situation, it is rarely considered in the value co-creation activities from the perspective of customers. Furthermore, it is valuable to identify the connotation of person-environment fit in the service interaction context and the role in value co-creation. In fact, with the development of information technology, plenty of enterprises are using data mining technology and analysis technology to achieve a precise fit between customers and products. However, the products are not the only purpose of customers in the service interactions, and the display of the abilities and the value creation will be a serious matter.

The present study attempts to address these gaps by focusing on service interaction and examining its impact on customer value co-creation, which involves utilitarian and hedonic value. Building on two fit elements of person-job fit, we propose the concept of customer-task fit to explore the above mechanism, which includes a customer's demand-ability fit, which refers to how the customer's ability matches the value co-creation requirement, and customer's needs-supply fit, which refers to the match a customer perceives between desired rewards and those offered by the company. More specifically, we propose to inspect demand-ability fit and needs-supply fit as serial mediators of the relationship between service interaction and customer value co-creation.

\section{THEORETICAL BASIS AND HYPOTHESIS}

We use the person-environment fit theory (Kristof, 1996) as the theoretical basis of our model. The concept of fit is sometimes regarded as similarity or consistency, but Muchinsky and Monahan (1987) argued that it is incomplete to understand the fit as the degree of consistency between person and environment, and they proposed two different types of fits: complementary fit and supplementary fit. Complementary fit means that a mutual compensation mode can be formed between person and environment to achieve an effective match. Muchinsky and Monahan clarified it as demand-ability fit, referring to the ability of a person to meet the requirements of the environment. In addition, Kristof developed the concept of complementary fit by proposing needs-supply fit, which means that a person can help an organization meet requirements or an organization can satisfy a person's 
needs (Kristof, 1996). Then, the supplementary fit refers to the compatibility of a person with the organization or environment.

From the perspective of value co-creation, customers are often regarded as part-time employees, who create value together with companies. Dong et al. (2015) argue that person-job fit provides the most relevant theoretical approach for the value co-creation context, and good customer-task fit arises when they have the right ability (demand-ability fit) to participate and perceive acceptable rewards (needs-supply fit). The task is similar to a job, and the value is co-created mostly through the interactions between service providers and customers in the service joint sphere. According to person-job fit, these lead to better performance and greater satisfaction (Kristof, 1996).

\subsection{Service Interaction and Customer Value Co-Creation}

In the service context, interaction means that two or more participants are in contact with each other for a business reason, and they have the opportunity to influence each other's processes (Grönroos \& Ravald, 2009). Furthermore, Ivanova-Gongne (2015) interpreted service interaction as an expression between employees and customers through attitudes, dialogues, and gestures. Service interaction has received a lot of attention, and then interactive customers can directly invest in services, gain more choices, and co-create high-level customized products or services with employees (Auh et al., 2007). Service interaction has some advantages, including guaranteeing service quality, enhancing profitability, reducing risks (Etgar, 2008), and producing more rational economic value (Chan et al., 2010).

Based on cognitive psychology, Holbrook and Hirschman (1982) proposed that customers do not always make their decisions in terms of rational assessments. They used hedonic consumption related to products or services providing aesthetic, emotional, or symbolic value to customers, in contrast to utilitarian offerings. Parasuraman et al. (2005) focused on the experience of pleasure, affection and fun in the research of service contacts. Then, customer participation is inherently attractive and enjoyable (Dabholkar \& Bagozzi, 2002), and it can help them control service processes and outcomes (Dabholkar, 1990). Further, from the flow experience theory and learning perspective, Chi and Lam (2012) argued that interactions between customers and employees can enhance customers' participation enjoyment.

Therefore, in the service interaction context, the customers can express their own requirements, and the employees communicate with them, which is conducive to formulating and improving the solution that meets customer needs, then, the outcomes of service will be more utilitarian. Moreover, customers can make the interaction smoother by their abilities, result in desirable services, which can enhance their hedonic experience. Thus, the following hypotheses are proposed.

Hypothesis 1a: Service interaction relates positively to utilitarian value.

Hypothesis 1b: Service interaction relates positively to hedonic value.

\subsection{Service Interaction, Demand-Ability Fit, and Value Co-Creation}

From organizational research, demand-ability fit refers to the degree that an individual is suitable for organizational requirements in terms of effort, commitment, experience, knowledge, and skills and has a significant predictive effect on job satisfaction (Chapman et al., 2005), and suggest that task-relevant abilities are necessary to manage the ever-increasing requirements of complex work situations. This is true not only for cognitive but also for perceptual and motor competencies (Trautmann et al., 2011), such as the ability to learn new tasks or to perform well-learned complex tasks in changing contexts. The theory of work adjustment (TWA) argues that individuals engage in adjustment behaviors aimed at achieving fit between their abilities and job requirements (Yu, 2016).

From the customer participation (CP) research, good customer demand-ability fit means customers have the right ability to perform the task (Dong et al., 2015). Mostly, the purpose of 
interaction is to solve the problems that cannot be solved by the customer or employee alone. In service interaction, customer can get experience, knowledge, and skills that enhance their perception and agency. Therefore, interaction is a learning process, which can effectively improve the knowledge and ability of the customer. Dahl and Moreau (2007) argued that providing instructions to customers during the service process can enhance their ability to understand the rules and makes appropriate behavioral plans to achieve related tasks. Furthermore, when the abilities of a person fit the task requirements, it will lead to flow experience (Nakamura \& Csikszentmihalyi, 2002). Dabholkar (1990) believed that when customers participate in the process of co-creation and control the service process and outcomes, it will result in positive emotions, because it makes one feel like an expert, generating positive emotions and pleasant experiences (Dahl \& Moreau, 2007).

There are some similar studies of customer abilities and task requirements, such as the concept of smart shopping, which means that consumers spend a lot of time and effort searching and using promotion-related information to save money (Mano \& Elliott, 1997). When consumers attribute the savings to their shopping skills and efforts, smart shopping will influence the perceived value. Therefore, in the process of service interaction, an employee can get timely feedback from the customer, and the customer can obtain relevant information and knowledge, making it possible to obtain better capabilities and more information to improve work efficiency. Thus, the following hypotheses are proposed.

Hypothesis 2a: Demand-ability fit mediates the relationship between service interaction and utilitarian value.

Hypothesis 2b: Demand-ability fit mediates the relationship between service interaction and hedonic value.

\subsection{Service Interaction, Needs-Supply Fit and Customer Value Co-Creation}

Based on the desires-supplies perspective, needs-supply fit refers to "a result of an environment adequately meeting individual's needs" (Shen et al., 2018). From the CP research, needs-supply fit reflects the fit between customers' preferences and offerings attributes (Moon \& Lee, 2014). Service interactions can help firms understand customers' thoughts and identify their demands (Lusch \& Vargo, 2006), and the main purpose is to find and provide matching products or services for customers (Dong et al., 2015).

Along with the arrival of information times, many retailers implementing customization, such as IKEA (furniture) and Trip.com (tourism services), offer several options in terms of the product's design features. Therefore, service interactions can create solutions to meet the customized needs of customers (Chan et al., 2010), which means customer need for a unique product (or service) can be satisfied with high probability because it enables them to select and match their need from a set of options supplied by the employees. Therefore, customers may derive more benefits from interaction if there is a stronger fit between their preferences and the attributes of customized offerings (Simonson, 2005).

More choices mean more participation and that products or services have been screened and refined many times, which takes place to provide service and mutual benefit in actor-to-actor interactions (Vargo \& Lusch, 2008). Then, the offerings will be more useful or save costs, meaning higher utilitarian value. Furthermore, when the products or services match customer preferences with their efforts, customers will consider their efforts to be positive (Franke et al., 2010), encouraging customers to be more engaged, arousing their sensory experiences, and leading to positive emotional effects (Benlian, 2015). Thus, the following hypotheses are proposed.

Hypothesis 3a: Needs-supply fit mediates the relationship between service interaction and utilitarian value. 
Hypothesis 3b: Needs-supply fit mediates the relationship between service interaction and hedonic value.

\subsection{Serial Mediation Effect of Demand-Ability Fit and Needs-Supply Fit}

We also propose a serial mediation effect of customer demand-ability fit and needs-supply fit on the relationship between service interaction and value co-creation, based on the argument that demandability fit may not directly result in value co-creation. Demand-ability fit has been identified as one of the essential conditions for creativity and job satisfaction by Livingstone et al. (1997). According to some research findings, customer demand-ability fit may enhance co-creation passion and make them expend more effort in their task to produce better outcomes (Dong et al., 2015). For instance, $\mathrm{Yu}$ (2016) provided empirical support for the positive relationship between demand-ability fit and needs-supply fit. More specifically, a customer with the right ability (demand-ability fit) refers to the knowledge and skills that enable he/she to participate effectively (Meuter et al., 2005;Dong et al., 2015), which in turn would lead to creating suitable products or services, and they would benefit in these processes and outcomes, including extrinsic rewards, such as monetary discounts and convenience (Meuter et al., 2005) and intrinsic rewards, such as enjoyment and a sense of accomplishment (Lusch et al., 1992). In contrast, those whose abilities do not match requirements (i.e., poor demand-ability fit) are usually ostracized and undermined at work, making them less likely to be rewarded with supplies that satisfy their needs (Yu, 2016).

Based on the person-environment fit theory, Dawis and Lofquist (1984) summarized the methods used to increase fit, which include proactive adjustment strategies and reactive strategies. In the service interaction context, customers may increase correspondence by changing aspects of the products or services (adjustment strategies) and change aspects themselves in order to increase levels of fit (reactive strategies). Meanwhile, customer learning in interactions could lead to ability improvement and improve these two strategies. Because, for the service to be delivered, the customer still must learn to use, maintain, repair, and adapt the appliance to his or her unique needs, usage situation, and behaviors (Vargo \& Lusch, 2004). Therefore, we anticipate that the relationship of service interaction and value co-creation is sequentially mediated by demand-ability fit and needs-supply fit. Hence, we hypothesize the following:

Hypothesis 4a: Demand-ability fit and needs-supply fit serially mediate the relationship between service interaction and utilitarian value.

Hypothesis 4b: Demand-ability fit and needs-supply fit serially mediate the relationship between service interaction and hedonic value.

The hypothesized research model is presented in Figure 1.

\section{METHOD}

\subsection{Sample and Procedures}

We used the customer survey method to test hypotheses and required subjects to recall the service interaction that took place within a week so they can still remember the details. Program control and statistical control are used to minimize the common method bias. For the program control, constructs were physically separated in the questionnaire, anonymity was provided, and respondents were assured that there are no right or wrong answers (Podsakoff et al., 2003). A total of 595 questionnaires were retrieved from China, and 86 invalid ones that had not been carefully answered were excluded. The final number of valid questionnaire responses was 509 , and the effective response rate was $85.5 \%$. As for the samples, males accounted for $53.6 \%$ of the total, and females, $46.4 \%$. In terms of age, $16.2 \%$ were below 20 years old, $45.8 \%$ from $21-30$ years old, $32.6 \%$ from $31-40$ years old, and $5.4 \%$ 


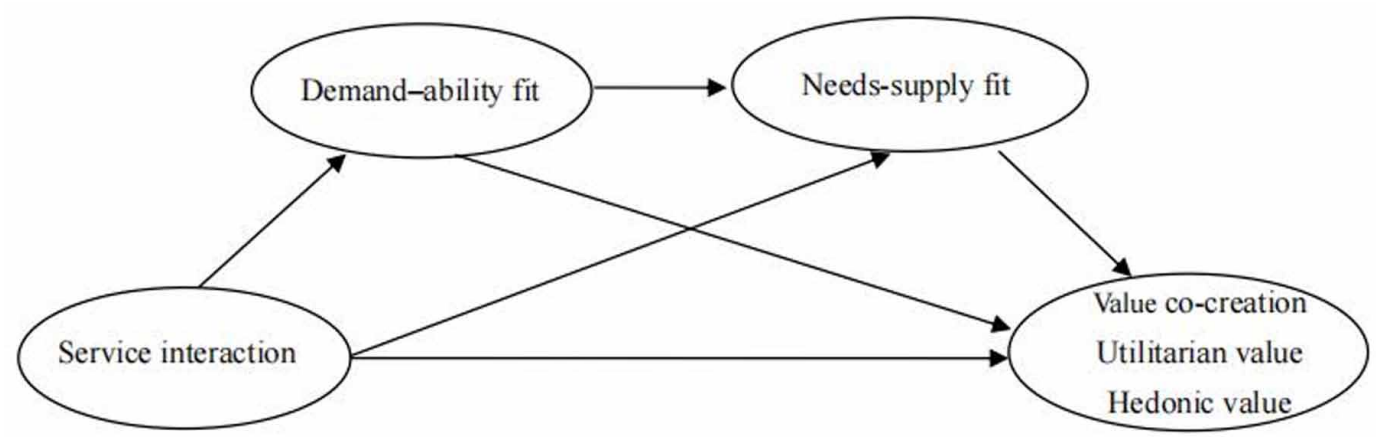

above 40 years old. In terms of education, $23.4 \%$ had a junior college or lesser degree, $39.7 \%$ had a college degree, and $36.9 \%$ had a postgraduate or higher degree. In terms of personal income, those with 3,000 yuan or below accounted for $29.6 \%$, those with 3,001-5,000 yuan for $30.7 \%$, those with 5,001 yuan or above for $39.7 \%$. Service industries include finance (16.9\%\%), shopping (22.0\%), medical treatment $(8.1 \%)$, logistics $(9.6 \%)$, decoration $(7.5 \%)$, tourism $(7.9 \%)$, telecommunication $(19.6 \%)$, and others $(8.4 \%)$.

\subsection{Measure Operationalization}

The original measures were presented in English and then translated into Chinese using the standard back-translation (Brislin, 1980) for distribution. Questionnaires were appropriately modified in accordance with the purpose of this work. All items used a seven-point Likert scale $(1=$ strongly disagree, and $7=$ strongly agree $)$.

After adopting a behavioral approach to capture service interaction, we measured the extent to which the customer interacts with the employee with five items: "I spent a lot of time to communicate with the employee," "I put a lot of effort into expressing my demand information," "I always provide suggestions to the employee for improving the service outcome," "the employee's feedback behavior is positive," and "the employee actively solve problems for me" (Chan et al., 2010; Wang \& Wan, 2012).

For customer demand-ability fit, we measured the extent to which customer abilities, skills, and efficiency meet the requirements in the service process (Dahl \& Moreau, 2007). Based on the measurement of the fit between the customer and the service or product, we used three items to measure customer needs-supply fit: "The service process looks really great," "The service offerings come close to my preference," and "I like the outcome of this service" (Franke et al., 2010; Moon and Lee, 2014). The utilitarian value scale includes convenient, economical, and quality (Ryu et al., 2013), and the hedonic value scale includes enjoyment, fun, and happiness (Chi \& Lam, 2012).

\section{RESULTS}

\subsection{Scale Reliability and Validity}

This work used confirmatory factor analysis for reliability and validity test. Table 1 shows the Cronbach's $\alpha$ value, composite reliability (CR), and average variance extracted (AVE). In terms of reliability, the Cronbach's $\alpha$ values of the variables in this work are all greater than 0.8 , which satisfies the requirements. In terms of validity, CR value and AVE value meet the requirements. 
Table 1. Reliability and validity

\begin{tabular}{|l|c|c|c|}
\hline \multicolumn{1}{|c|}{ Variable } & Cronbach's $\boldsymbol{\alpha}$ & CR & AVE \\
\hline Service interaction & 0.836 & 0.84 & 0.53 \\
\hline Needs-supply fit & 0.935 & 0.94 & 0.78 \\
\hline Demand-ability fit & 0.938 & 0.94 & 0.79 \\
\hline Utilitarian value & 0.955 & 0.96 & 0.84 \\
\hline Hedonic value & 0.949 & 0.95 & 0.82 \\
\hline
\end{tabular}

\subsection{Common Method Bias}

The common method bias is tested by marker variable analysis (Lindell \& Whitney, 2001), and the monthly income is adopted as the marker variable. Table 2 shows the correlation coefficient matrix of the marker variable and other variables. The correlation coefficient between the marker variable and other variables is low, and there is no significant correlation $(p>0.05)$. That is, the common method bias in this work is not serious.

\subsection{Hypothesis Test}

\subsubsection{Main Effect Test}

We used ordinary least squares (OLS) regression analysis to test Hypothesis 1a and Hypothesis 1b, and the control variables included gender, age, educational background, and service industries. Table 3 shows that service interaction relates positively to utilitarian value $(\beta=0.541, P<0.001)$ and hedonic value $(\beta=0.542$, and $P<0.001)$. Thus, Hypothesis $1 \mathrm{a}$ and Hypothesis $1 \mathrm{~b}$ are supported.

\subsubsection{Mediation Effect Test}

The bootstrap method was used to test the mediation effects, with the macro-analysis process developed by Hayes et al. Using the Model 4 and bias-corrected methods, the samples were set at 5,000, with a confidence interval of $95 \%$, and the control variables included gender, age, educational background, and service industries. Table 4 shows the results of the bootstrap test. The left side shows the indirect effects of the two mediators (in parallel) between service interaction and utilitarian value. The right side shows the indirect effects of the two mediators (in parallel) between service interaction and hedonic value.

The data results show that, first, as for the relationship between the service interaction and the utilitarian value, the overall mediation effect of the two mediators is significant, with a $95 \%$

Table 2. Correlation coefficient matrix

\begin{tabular}{|l|l|l|l|l|l|l|}
\hline & \multicolumn{1}{|c|}{ SI } & \multicolumn{1}{c|}{ NSF } & \multicolumn{1}{c|}{ DAF } & \multicolumn{1}{c|}{ UV } & \multicolumn{1}{c|}{ HV } & INCO \\
\hline SI & 1 & & & & & \\
\hline NSF & $0.573^{* *}$ & 1 & & & & \\
\hline DAF & $0.528^{* *}$ & $0.624^{* *}$ & 1 & & & \\
\hline UV & $0.549 * *$ & $0.789^{* *}$ & $0.632^{* *}$ & 1 & & \\
\hline HV & $0.547^{* *}$ & $0.766^{* *}$ & $0.729 * *$ & $0.795^{* *}$ & 1 & 1 \\
\hline INCO & 0.097 & 0.047 & 0.025 & 0.047 & 0.053 & 1 \\
\hline
\end{tabular}

Notes: $\mathrm{SI}=$ service interaction; $\mathrm{NSF}=$ needs-supply fit; $\mathrm{DAF}=$ demand-ability fit; $\mathrm{UV}=$ utilitarian value; $\mathrm{HV}=$ hedonic value; INCO = monthly income. ** $P<0.01$ (two-tailed test). 
Table 3. Main effect test

\begin{tabular}{|c|c|c|c|c|c|c|c|c|}
\hline \multirow{3}{*}{ IV } & \multicolumn{4}{|c|}{ DV1: Utilitarian value } & \multicolumn{4}{|c|}{ DV2: Hedonic value } \\
\hline & \multicolumn{2}{|c|}{ Model 1} & \multicolumn{2}{|c|}{ Model 2} & \multicolumn{2}{|c|}{ Model 3} & \multicolumn{2}{|c|}{ Model 4} \\
\hline & $\boldsymbol{\beta}$ & VIF & $\boldsymbol{\beta}$ & VIF & $\boldsymbol{\beta}$ & VIF & $\boldsymbol{\beta}$ & VIF \\
\hline Gender & -0.070 & 1.028 & -0.050 & 1.019 & $-0.105^{*}$ & 1.028 & $-0.086^{*}$ & 1.029 \\
\hline Age & $0.115^{*}$ & 1.031 & 0.044 & 1.046 & 0.070 & 1.031 & -0.000 & 1.048 \\
\hline Education & -0.084 & 1.012 & $-0.089^{*}$ & 1.008 & $-0.134 * *$ & 1.012 & $-0.139 * * *$ & 1.012 \\
\hline Industries & -0.007 & 1.010 & -0.024 & 1.010 & 0.019 & 1.010 & 0.013 & 1.010 \\
\hline Service interaction & & & $0.541 * * *$ & 1.020 & & & $0.542 * * *$ & 1.020 \\
\hline$R^{2}$ & \multicolumn{2}{|l|}{0.030} & \multicolumn{2}{|l|}{0.316} & \multicolumn{2}{|l|}{0.038} & \multicolumn{2}{|l|}{0.326} \\
\hline$\Delta R^{2}$ & \multicolumn{2}{|l|}{$0.030^{*}$} & \multicolumn{2}{|l|}{$0.287 * * *$} & \multicolumn{2}{|l|}{$0.030^{* *}$} & \multicolumn{2}{|l|}{$0.319 * * *$} \\
\hline$F$-value & \multicolumn{2}{|l|}{$3.862 *$} & \multicolumn{2}{|c|}{$210.924 * * *$} & \multicolumn{2}{|l|}{$4.938 * * *$} & \multicolumn{2}{|l|}{$214.789 * * *$} \\
\hline
\end{tabular}

Note: ${ }^{*} P<0.05 ;{ }^{* *} P<0.01 ;{ }^{* *} P<0.001$

confidence interval $([0.5398,0.7408])$, excluding zero values. The indirect effects of needs-supply fit and demand-ability fit are 0.5344 and 0.1062 , respectively; they are all with $95 \%$ confidence intervals, excluding zero values. This supports Hypothesis $2 \mathrm{a}$ and Hypothesis $3 \mathrm{a}$. Secondly, as for the relationship between service interaction and hedonic value, the overall mediation effect of the two mediators is significant, with a $95 \%$ confidence interval ([0.5928, 0.8020]), excluding zero values. The indirect effects of needs-supply fit and demand-ability fit are 0.4354 and 0.2598 , respectively, with all 95\% confidence intervals excluding 0. This supports Hypothesis $2 \mathrm{~b}$ and Hypothesis $3 \mathrm{~b}$.

After controlling total two mediators, 95\% confidence interval of the direct effect of service interaction on utilitarian value excludes zero ([0.0021, 0.1555]), and the effect is $0.0788(p=0.0440)$. It indicates that two mediators together partially mediate the relationship between service interaction and utilitarian value. Moreover, after controlling the two mediators, the $95 \%$ confidence interval of the direct effect of service interaction on hedonic value includes zero ([-0.0135, 0.1501]), and the effect is 0.0683 ( $p=0.1015)$. It indicates that the two mediators together play the complete mediating role between service interaction and hedonic value.

Furthermore, the serial mediation model linking service interaction with value co-creation was tested using Model 6 of the SPSS process macro proposed by Hayes et al. Effect size estimates of indirect associations were drawn using bootstrap confidence intervals, and gender, age, educational background, service industries were entered as covariates in the process model. Total, direct, and indirect effects are provided in Table 5 and Table 6.

\section{Table 4. Mediation effect}

\begin{tabular}{|l|c|r|r|l|l|l|}
\hline & \multicolumn{3}{|c|}{ Utilitarian value } & \multicolumn{3}{c|}{ Hedonic value } \\
\hline \multirow{2}{*}{ Mediation effect } & \multirow{2}{*}{ Effect } & \multicolumn{2}{|c|}{$95 \%$ Confidence interval } & \multirow{2}{*}{ Effect } & \multicolumn{2}{c|}{$95 \%$ Confidence interval } \\
\cline { 6 - 8 } & & Lower limit & Upper limit & & Lower limit & Upper limit \\
\hline Overall mediation effect & 0.6406 & 0.5398 & 0.7408 & 0.6951 & 0.5928 & 0.8020 \\
\hline Needs-supply fit & 0.5344 & 0.4483 & 0.6272 & 0.4354 & 0.3506 & 0.5320 \\
\hline Demand-ability fit & 0.1062 & 0.0516 & 0.1712 & 0.2598 & 0.1918 & 0.3406 \\
\hline
\end{tabular}


Table 5. Total, direct, and indirect effects of service interaction on utilitarian value

\begin{tabular}{|l|c|c|c|c|}
\hline \multirow{2}{*}{ Indirect effect } & \multirow{2}{*}{ Effect } & \multirow{2}{*}{ Standard error } & \multicolumn{2}{c|}{ 95\% Confidence interval } \\
\cline { 4 - 5 } & & & Lower limit & Upper limit \\
\hline Total & 0.6406 & 0.0535 & 0.5398 & 0.7480 \\
\hline $\mathrm{SI} \rightarrow \mathrm{DAF} \rightarrow \mathrm{UV}$ & 0.1062 & 0.0304 & 0.0516 & 0.1712 \\
\hline $\mathrm{SI} \rightarrow \mathrm{DAF} \rightarrow \mathrm{NSF} \rightarrow \mathrm{UV}$ & 0.2169 & 0.0309 & 0.1638 & 0.2878 \\
\hline $\mathrm{SI} \rightarrow \mathrm{NSF} \rightarrow \mathrm{UV}$ & 0.3175 & 0.0429 & 0.2370 & 0.4058 \\
\hline Direct Effect & & & & 0.0021 \\
\hline SI $\rightarrow$ UV & 0.0788 & 0.0390 & & 0.1555 \\
\hline $\mathrm{R}-\mathrm{square}$ & & & & 0.3098 \\
\hline $\mathrm{DAF}$ & & & & 0.4764 \\
\hline $\mathrm{NSF}$ & & & & 0.7342 \\
\hline $\mathrm{UV}$ & & & & \\
\hline
\end{tabular}

Notes: SI, service interaction; NSF, needs-supply fit; DAF, demand-ability fit; UV, utilitarian value.

From Table 5, the indirect effect of service interaction on utilitarian value through the sequential effect of demand-ability fit and needs-supply fit was significant, with a 95\% confidence interval ([0.1638, 0.2878]), excluding zero values, and the effect is 0.2169 . Thus, this supports Hypothesis $4 \mathrm{a}$.

From Table 6, the indirect effect of service interaction on hedonic value through the sequential effect of demand-ability fit and needs-supply fit was significant, with a 95\% confidence interval ([0.1308, 0.2386]), excluding zero values, and the effect is 0.1767 . Thus, this supports Hypothesis $4 \mathrm{~b}$.

Table 6. Total, direct, and indirect effects of service interaction on hedonic value

\begin{tabular}{|l|c|c|c|c|}
\hline \multirow{2}{*}{ Indirect effect } & \multirow{2}{*}{ Effect } & \multirow{2}{*}{ Standard error } & \multicolumn{2}{c|}{ 95\% Confidence interval } \\
\cline { 4 - 5 } & & & Lower limit & Upper limit \\
\hline Total & 0.6951 & 0.0529 & 0.5928 & 0.8020 \\
\hline $\mathrm{SI} \rightarrow \mathrm{DAF} \rightarrow \mathrm{HV}$ & 0.2598 & 0.0380 & 0.1918 & 0.3406 \\
\hline $\mathrm{SI} \rightarrow \mathrm{DAF} \rightarrow \mathrm{NSF} \rightarrow \mathrm{HV}$ & 0.1767 & 0.0267 & 0.1308 & 0.2386 \\
\hline $\mathrm{SI} \rightarrow \mathrm{NSF} \rightarrow \mathrm{HV}$ & 0.2587 & 0.0399 & 0.1865 & 0.3454 \\
\hline $\mathrm{Direct} \mathrm{effect}$ & & & & 0.0135 \\
\hline $\mathrm{SI} \rightarrow \mathrm{HV}$ & 0.0683 & 0.0416 & & 0.1501 \\
\hline$R^{2}$ & & & & 0.3098 \\
\hline $\mathrm{DAF}$ & & & & 0.7304 \\
\hline $\mathrm{NSF}$ & & & & \\
\hline $\mathrm{HV}$ & & & & \\
\hline
\end{tabular}

Notes: SI, service interaction; NSF, needs-supply fit; DAF, demand-ability fit; HV, hedonic value. 


\section{DISCUSSION AND CONCLUSION}

\subsection{Theoretical Implications}

The empirical evidence supports that the person-environment fit (e.g., customer-task fit) is a prerequisite for the success of a firm's efforts to improve customer value co-creation by encouraging service interaction. In the service interaction context, the customer-task fit is proposed as customers' demand-ability fit and needs-supply fit, through which service interaction influences value cocreation. These findings are consistent with the prior research that fit is the key to achieving value co-creation (Strandvik et al., 2012; Gummesson \& Mele, 2010).

This work has several important contributions. Firstly, we developed and tested a theory-based integrative model of customer-task fit in the value co-creation process. Previous studies have made important contributions in identifying the influence of certain customers' fit with products and services and emphasizing the importance of fit regarding production evaluation (Strandvik et al., 2012). However, they lack theoretical explanations and empirical research. Based on the person-environment fit theory, this work explains how service interaction influences customer value co-creation. This contribution is important because a better understanding of these processes can provide insight into the sustained effects of service interaction strategies on value co-creation.

Secondly, we find a serial mediation model linking service interaction with value co-creation. Previous studies have found the importance of customers' demand-ability fit and needs-supply fit on service outcome (Dong et al., 2015). However, they did not analyze the relationship between demand-ability fit, needs-supply fit, and serial mediation effects. Clarifying the serial mediation effects of customer demand-ability fit and needs-supply fit on the relationship between service interaction and value co-creation can help us to further understand the role of customer-task fit in the value co-creation mechanism. Therefore, our findings offer a framework to capture a more complete picture of the service interaction - value co-creation link.

Thirdly, through empirical analysis, we find that different fit elements of customer-task fit have different mediation effects. In the service interaction context, customer needs-supply fit (Table 5, effect $=0.3175$ ) has a greater mediation effect than demand-ability fit (Table 5, effect $=0.1062$ ) on the relationship between service interaction and utilitarian value, but not significantly on the relationship between service interaction and hedonic value (NSF, 0.2587; DAF, 0.2598). It may be that utilitarian value is mainly reflected in the customer's subjective cognition of the function and economy of the product (or service), but hedonic value is mainly reflected in the service process. Thus, the demand-ability fit in this value co-creation process is relatively important.

\subsection{Managerial Implications}

Service interaction adds a new dynamic to the customer-provider relationship, which engages customers directly in the process of value co-creation. Many companies in China, such as Xiaomi, Alibaba, and Haier, have already operationalized interactions with their customers. With the assistance of various technologies (e.g., IT, Big Data, AI), they are getting better at doing these things. However, the key question is how to co-create value with customers through interactions. The findings have several implications for companies that are considering or have engaged their customers in the process of value co-creation.

Firstly, customer-task fit is the key for value co-creation, which is the most important performance within service interactions. Therefore, it is important not only to help customers choose the right product or service but also to provide a good service process in terms of service attitude (Kuo, 2007) and information quality (Yuan et al., 2018). Then, the provider should not only be familiar with the knowledge of product and service but also establish accurate access to information on customer preferences and other characteristics. Meanwhile, with the continuous development of the internet and social networks, the passive role of customers of information "receiving" has evolved to information "producers" (Hamidi \& Safareeyeh, 2019). In other words, realizing this two-way fit will become 
easy now. However, companies should become more cautious about product recommendation and information transfer because uncomfortable offerings and services would lead to bad word-of-mouth.

Secondly, customer abilities can be improved by service interaction, and this is a necessary condition for participating in value co-creation. Such a finding is in line with and qualifies the previous research on the fit between, or the consonance of, resources, activities, and processes, which can further influence value creation. Thus, it is necessary to classify customers according to their abilities, to allocate appropriate resources for value co-creation. Meanwhile, companies also need to enhance customer co-creation capabilities, for example, by providing necessary information and training in the early stages. However, excessive investments of unrelated resources will be a waste and will not be popular with customers. For example, some software functions are too complex, making it feel tedious for customers to participate in product design. Some multinational companies in China were the first to adopt customized tools to involve customers in the process of product design and production, in order to better understand customers, localization strategies would be a good choice, which refers to employees, tools, and processes.

Thirdly, Chinese people are usually reserved to keep their feelings hidden, and so is the information searching process of customers. Thus, how to make customers open their hearts is very important. Therefore, the employees should improve their emotional intelligence and empathy in order to gain the trust of customers (Rahman et al., 2020), which would meet customer needs in timely and accurate ways and reduce transaction costs and the input of unnecessary resources. Sometimes, it is difficult for providers to understand the customer's needs and behaviors, including linguistic and non-verbal expressions, but this problem can be solved by improving the ability of service providers or using artificial intelligence.

Overall, our findings support the notion that strategies promoting service interaction can play an important role in value co-creation. In this actor-to-actor exchange system, when different forms of information exchange, collaboration, and cooperation occur between a company and its customers (Nardi et al., 2019), the company can target service interaction indirectly or target customer-task fit directly to improve value co-creation. Furthermore, the company can use information technology and other tools to promote the fit of resources, processes, and goals in value co-creation. For example, social network tools make it easier for companies to exchange information with customers. With the help of business platforms and big data technologies, companies can better understand their customers. Therefore, those companies that pay for Taobao's "portrait of the consumers" information service will have an advantage against their competition.

\subsection{Limitations and Further Research}

The generalizability of the findings should be considered in light of our study's limitations. The findings are more suggestive than conclusive. This work does not consider other environmental factors, such as the comfort level of the environment, the ability and professional level of the employees, and the cultural differences between the two parties, which will definitely influence the value co-creation process. Also, the collection of employee information is what we need to do in future research, which will help us understand service interactions more profoundly. Further, the nonlinear relationship between service interaction, customer-task fit, and value co-creation should be considered.

\section{ACKNOWLEDGMENT}

This research was supported by the Fundamental Research Funds for Zhejiang Provincial Universities and the First Research and Innovation Team Funding of "Sustainable Supply Chain Management and Innovation" in Zhejiang Wanli University, Natural Science Foundation of China (71772183), Natural Science Foundation for Youths of Anhui Province (1808085QG230), Anhui Philosophy and Social Science Planning Project (AHSKY2019D029). 


\section{REFERENCES}

Auh, S., Bell, S. J., McLeod, C. S., \& Shih, E. (2007). Co-production and customer loyalty in financial services. Journal of Retailing, 83(3), 359-370. doi:10.1016/j.jretai.2007.03.001

Bendapudi, N., \& Leone, R. P. (2003). Psychological implications of customer participation in co-production. Journal of Marketing, 67(1), 14-28. doi:10.1509/jmkg.67.1.14.18592

Benlian, A. (2015). Web personalization cues and their differential effects on user assessments of website value. Journal of Management Information Systems, 32(1), 225-260. doi:10.1080/07421222.2015.1029394

Bhat, Z. H., \& Rainayee, R. A. (2017). Examining the mediating role of person-job fit in the relationship between training and performance: A civil servant perspective. Global Business Review, 20(2), 1-19.

Brislin, R. W. (1980). Translation and content analysis of oral and written materials. In H. C. Triandis \& J. W. Berry (Eds.), Handbook of Cross-Cultural Psychology (Vol. 2, pp. 389-444). Allyn \& Bacon.

Chan, K. W., Chi, K. Y., \& Lam, S. S. K. (2010). Is customer participation in value creation a double-edged sword? Evidence from professional financial services across cultures. Journal of Marketing, 74(3), 48-64. doi:10.1509/jmkg.74.3.048

Chapman, D. S., Uggerslev, K. L., Carroll, S. A., Piasentin, K. A., \& Jones, D. A. (2005). Applicant attraction to organizations and job choice: A meta-analytic review of the correlates of recruiting outcomes. The Journal of Applied Psychology, 90(5), 928-944. doi:10.1037/0021-9010.90.5.928 PMID:16162065

Cheng-Ping, L. (2018). Study on the relationship among recreational environmental fit, situational involvement, recreational satisfaction, and revisiting intention of participants in the 2017 sun moon lake swimming carnival. International Journal of Organizational Innovation, 10, 101-119.

Chi, K. Y., \& Lam, S. S. K. (2012). Do customers and employees enjoy service participation? Synergistic effects of self- and other-efficacy. Journal of Marketing, 76(6), 121-140. doi:10.1509/jm.11.0205

Dabholkar, P. A. (1990). How to improve perceived service quality by increasing customer participation. In B. J. Dunlap (Ed.), Developments in Marketing Science (Vol. 13, pp. 483-487). Academy of Marketing Science.

Dabholkar, P. A., \& Bagozzi, R. P. (2002). An attitudinal model of technology-based self-service: Moderating effects of consumer traits and situational factors. Journal of the Academy of Marketing Science, 30(3), 184-201. doi:10.1177/0092070302303001

Dahl, D. W., \& Moreau, C. P. (2007). Thinking inside the box: Why consumers enjoy constrained creative experiences. JMR, Journal of Marketing Research, 44(3), 357-369. doi:10.1509/jmkr.44.3.357

Davey, J., \& Gronroos, C. (2019). Health service literacy: Complementary actor roles for transformative value co-creation. Journal of Services Marketing, 33(6), 687-701. doi:10.1108/JSM-09-2018-0272

Dawis, R. V., \& Lofquist, L. H. (1984). A psychological theory of work adjustment. University of Minnesota Press.

Dong, B., Sivakumar, K., Evans, K. R., \& Zou, S. (2015). Effect of customer participation on service outcomes: The moderating role of participation readiness. Journal of Service Research, 18(2), 160-176. doi:10.1177/1094670514551727

Ennew, C. T., \& Binks, M. R. (1999). Impact of participative service relationships on quality, satisfaction and retention: An exploratory study. SMF Discussion Paper, 46(2), 121-132.

Etgar, M. (2008). A descriptive model of the consumer co-production process. Journal of the Academy of Marketing Science, 36(1), 97-108. doi:10.1007/s11747-007-0061-1

Franke, N., Schreier, M., \& Kaiser, U. (2010). The "I designed it myself" effect in mass customization. Management Science, 56(1), 125-140. doi:10.1287/mnsc.1090.1077

Gander, F., Hofmann, J., \& Ruch, W. (2020). Character strengths: Person-environment fit and relationships with job and life satisfaction. Frontiers in Psychology, 11, 1582. doi:10.3389/fpsyg.2020.01582 PMID:32793038

Grönroos, C., \& Ravald, A. (2009). Marketing and the logic of service: Value facilitation, value creation and co-creation, and their marketing implications. Working Papers, 9(1), 131-134. 
Grönroos, C., \& Voima, P. (2013). Critical service logic: Making sense of value creation and co-creation. Journal of the Academy of Marketing Science, 41(2), 133-150. doi:10.1007/s11747-012-0308-3

Gummesson, E., \& Mele, C. (2010). Marketing as value co-creation through network interaction and resource integration. Journal of Business Market Management, 4(4), 181-198. doi:10.1007/s12087-010-0044-2

Guo, G. Q., \& Sun, N. J. (2012). An empirical study on the influence of perceived interaction types on experience value under new entrepreneur adaptation intermediary. Management Review, 24(12), 72-83.

Hamidi, H., \& Safareeyeh, M. (2019). A model to analyze the effect of mobile banking adoption on customer interaction and satisfaction: A case study of m-banking in Iran. Telematics and Informatics, 38, 166-181. doi:10.1016/j.tele.2018.09.008

Holbrook, M. B., \& Hirschman, E. C. (1982). The experiential aspects of consumption: Consumer fantasies, feelings, and fun. The Journal of Consumer Research, 9(2), 132. doi:10.1086/208906

Ivanova-Gongne, M. (2015). Culture in business relationship interaction: An individual perspective. Journal of Business and Industrial Marketing, 30(5), 608-615. doi:10.1108/JBIM-01-2013-0002

Kristof, A. L. (1996). Person-organization fit: An integrative review of its conceptualizations, measurement, and implications. Personnel Psychology, 49(1), 1-49. doi:10.1111/j.1744-6570.1996.tb01790.x

Kristof-Brown, A. L., Zimmerman, R. D., \& Johnson, E. C. (2005). Consequences of individuals' fit at work: A meta-analysis of person-job, person-organization, person-group, and person-supervisor fit. Personnel Psychology, 58(2), 281-342. doi:10.1111/j.1744-6570.2005.00672.x

Kuo, C.-M. (2007). The importance of hotel employee service attitude and the satisfaction of international tourists. Service Industries Journal, 27(8), 1073-1085. doi:10.1080/02642060701673752

Lindell, M. K., \& Whitney, D. J. (2001). Accounting for common method variance in cross-sectional research designs. The Journal of Applied Psychology, 86(1), 114-121. doi:10.1037/0021-9010.86.1.114 PMID:11302223

Livingstone, L. P., Nelson, D. L., \& Barr, S. H. (1997). Person-environment fit and creativity: An examination of supply-value and demand-ability versions of fit. Journal of Management, 23(2), 119-146. doi:10.1177/014920639702300202

Lovelock, C., \& Wirtz, J. (2010). Services marketing: People, technology, strategy (7th ed.). Prentice hall.

Lusch, R. F., Brown, S. W., \& Brunswick, G. J. (1992). A general framework for explaining internal vs. external exchange. Journal of the Academy of Marketing Science, 20(2), 119-134. doi:10.1007/BF02723452

Lusch, R. F., \& Vargo, S. L. (2006). Service-dominant logic: Reactions, reflections and refinements. Marketing Theory, 6(3), 281-288. doi:10.1177/1470593106066781

Mano, H., \& Elliott, M. T. (1997). Smart shopping: The origins and consequences of price savings. Advances in Consumer Research. Association for Consumer Research (U. S.), 24(1), 504-510.

Meuter, M. L., Bitner, M. J., Ostrom, A. L., \& Brown, S. W. (2005). Choosing among alternative service delivery modes: An investigation of customer trial of self-service technologies. Journal of Marketing, 69(2), 61-83. doi:10.1509/jmkg.69.2.61.60759

Moon, H., \& Lee, H. H. (2014). Consumers' preference fit and ability to express preferences in the use of online mass customization. Journal of Research in Interactive Marketing, 8(2), 27-32. doi:10.1108/JRIM-07-2013-0043

Muchinsky, P. M., \& Monahan, C. J. (1987). What is person environment congruence? Supplementary versus complementary models of fit. Journal of Vocational Behavior, 31(3), 268-277. doi:10.1016/0001-8791(87)900431

Nakamura, J., \& Csikszentmihalyi, M. (2002). The concept of flow. In C. R. Snyder \& S. J. Lopez (Eds.), Handbook of positive psychology (pp. 89-105). Oxford University Press.

Nardi, M. V., Jardim, W., Ladeira, W., \& Santini, F. (2019). Customer interaction in business relations: A meta-analysis approach. Marketing Intelligence \& Planning, 38(2), 239-253. doi:10.1108/MIP-11-2018-0531

Parasuraman, A., Zeithaml, V. A., \& Malhotra, A. (2005). A multiple-item scale for assessing electronic service quality. Journal of Service Research, 7(3), 213-233. doi:10.1177/1094670504271156 
Podsakoff, P. M., MacKenzie, S. B., Lee, J. Y., \& Podsakoff, N. P. (2003). Common method biases in behavioral research: A critical review of the literature and recommended remedies. The Journal of Applied Psychology, 88(5), 879-903. doi:10.1037/0021-9010.88.5.879 PMID:14516251

Rahman, M. S., Hossain, M. A., Zaman, M. H., \& Mannan, M. (2020). E-service quality and trust on customer's patronage intention: Moderation effect of adoption of advanced technologies. Journal of Global Information Management, 28(1), 39-55. doi:10.4018/JGIM.2020010103

Randall, R. M. (2004). The new competitive advantage: learning to co-create with customers. Strategy \& Leadership, 32(3).

Ryu, K. S., Han, H. S., \& Jang, S. C. (2013). Relationships among hedonic and utilitarian values, satisfaction and behavioral intentions in the fast-casual restaurant industry. International Journal of Contemporary Hospitality Management, 22(3), 416-432. doi:10.1108/09596111011035981

Shen, X. L., Li, Y. J., Sun, Y., \& Zhou, Y. (2018). Person-environment fit, commitment, and customer contribution in online brand community: A nonlinear model. Journal of Business Research, 85, 117-126. doi:10.1016/j. jbusres.2017.12.007

Shostack, G. L. (1985). Planning the service encounter. In J. A. Czepiel, M. R. Solomon, \& C. F. Surpernant (Eds.), The service encounter (pp. 89-105). Lexington Books.

Simonson, I. (2005). Determinants of customers' responses to customized offers: Conceptual framework and research propositions. Journal of Marketing, 69(1), 32-45. doi:10.1509/jmkg.69.1.32.55512

Strandvik, T., Holmlund, M., \& Bo, E. (2012). Customer needing: A challenge for the seller offering. Journal of Business and Industrial Marketing, 27(2), 132-141. doi:10.1108/08858621211196994

Trautmann, M., Voelckerrehage, C., \& Godde, B. (2011). Fit between workers' competencies and job demands as predictor for job performance over the work career. Journal for Labour Market Research, 44(4), 339-347. doi:10.1007/s12651-011-0078-2

Van Vianen, A. E. M. (2018). Person-environment fit: A review of its basic tenets. Annual Review of Organizational Psychology and Organizational Behavior, 5(1), 75-101. doi:10.1146/annurev-orgpsych-032117-104702

Vargo, S. L., \& Lusch, R. F. (2004). Evolving to a new dominant logic for marketing. Journal of Marketing, 68(1), 1-17. doi:10.1509/jmkg.68.1.1.24036

Vargo, S. L., \& Lusch, R. F. (2008). Service-dominant logic: Continuing the evolution. Journal of the Academy of Marketing Science, 36(1), 1-10. doi:10.1007/s11747-007-0069-6

Wang, X. X., \& Wan, W. H. (2012). Research on the mechanism of creating value in consumption field and its role in brand loyalty. Management Science, 25(5), 52-65.

Yu, K. Y. T. (2016). Inter-relationships among different types of person-environment fit and job satisfaction. Applied Psychology, 65(1), 38-65. doi:10.1111/apps.12035

Yuan, X., Chu, K., \& Cai, S. (2018). When is information quality more important? The moderating effects of perceived market orientation and shopping value. Journal of Global Information Management, 26(2), $204-232$. doi:10.4018/JGIM.2018040110 
Liang Hong, Doctor of Management, got his Ph.D degree from China in 2020. His research interests include Sensory Marketing and Customer Participation. His teaching courses cover Marketing Management and Logistics management.

Hongyan Yu, Professor in Marketing, got his Ph.D degree from China in 1996. His research interests cover customer experience, online community and food marketing. He has published papers in the Journal of Macro marketing, Journal of Consumer Behavior, European Journal of Marketing and several Chinese journals. His teaching courses cover Marketing Management, Marketing Research, Research Methods and Adverting. Dr.Yu has won awards and prizes of teaching on provincial and national level.

Yubing Yu is an Associate Professor at School of Logistics and E-commerce, Zhejiang Wanli University, China. He received his $\mathrm{PhD}$ degree in operations management from Zhejiang University. His research interests are mainly in supply chain quality and green management. His research has been published or accepted in many SCI/SSCl journals, such as Supply Chain Management: An International Journal, Production Planning \& Control, Technological Forecasting and Social Change, Journal of Cleaner Production, Total Quality Management \& Business Excellence, Journal of Enterprise Information Management, International Journal of Logistics Management, International Journal of Logistics Research and Applications. Yubing Yu is the corresponding author of this paper.

Peipei Liang, Associate Professor of Management, got his Ph.D degree from China in 2016. His research interests cover business model innovation, manufacturing servization and marketing. He has published papers in Advances in Production Engineering \& Management, Journal of Industrial Engineering and Management, China Journal of Operations Research and Management, etc.

Junjie Xu graduated from Beijing University of Posts and Telecommunications with a doctoral degree in 2007. At present, he is engaged in teaching and scientific research in Anqing Normal University, mainly studying e-commerce and logistics management. 